Review Article

\title{
A REVIEW ON PYRAZOLINE DERIVATIVES AS ANTIMICROBIAL AGENT
}

\author{
SARAS KUMAR JAIN*, ROHIT SINGHAL
}

LBS College of Pharmacy, Jabalpur (M. P.), Department of Pharmacy, Oriental University, Indore (M. P.)

Email: saras.jain1@gmail.com

Received: 15 Mar 2020, Revised and Accepted: 04 May 2020

\section{ABSTRACT}

At present, there is a lot of research about the pyrazoline heterocyclic compound, its ring structure is being changed and new derivatives are being made, many of which have antimicrobial activity over the derivatives. Pyrazoline is the five-member heterocyclic ring which have two $\mathrm{N}$ atoms in nearby position and contains two endocyclic double bonds. Noteworthy consideration has been concentrated on pyrazolines and pyrazoline derivative due to their important pharmacological action. Some replaced pyrazolines have been stated near retain particular important pharmacological actions as antimicrobial, antifungal, antineoplastic, antidepressant, insecticidal, anticonvulsant, anti-inflammatory, antibacterial and antitumor properties.

Keywords: Antimicrobial Activity, Pyrazoline, Heterocyclic Compound

(C) 2020 The Authors. Published by Innovare Academic Sciences Pvt Ltd. This is an open access article under the CC BY license (http://creativecommons.org/licenses/by/4.0/] DOI: http://dx.doi.org/10.22159/ijpps.2020v12i6.37456. Journal homepage: https://innovareacademics.in/journals/index.php/ijpps

\section{INTRODUCTION}

Microbial Infections (fungal and bacterial) have been informed to rise affected globally in present days and main causes are toward the block resistance. Both hospitalized and ambulatory patients are very needful of antimicrobials widespread. It is described that $24 \%$ to $40.8 \%$ of hospitalized persons accept them [1]. Destruction of resistance owing to several causes such as distortion, operations, immunosuppressive treatments, old age, HIV infection, is a reasonable sources that seats patients at great risk for transmittable contagious contaminations. This condition is exacerbated through growing rate of microbial conflict to the general antibiotics existing nowadays [2]. Antimicrobial altercation is a main anxiety, the threat to the community health in addition permits improvement and development of new and active antibiotics to challenge drug quarrel. To reveal these matters, there is a essential to develop new insignificant, harmless and effective drugs with a wide range of antimicrobial action [3]. There are several heterocyclic ring compounds having nitrogen atom such as pyrazole, pyrrolones, pyridazinones, pyrazolines have been considered generally used for the improvement of essential antimicrobial action. The powerful new drugs must been displayed to save lives when used to give some severe infections and to reduce the trouble of illness when used prophylactically in certain clinical situation. For the synthesis of new antibiotics, researcher effort lots on chemical compounds and pyrazoline derivatives are valuable as antimicrobial agents. Pyrazolines are enormously valuable nitrogen-containing heterocyclic compounds that occur in a diversity of chemical and biological agents and improve their activities. $\mathrm{N}-\mathrm{N}$ bond of the pyrazoline ring is restrained to be the important cause in their biological activities [4]. Pyrazoline can be defined as dihydro pyrazole having only one endocyclic double bond. On the basis of the position of the double bond three types of pyrazoline are possible: (i) 1-pyrazoline (ii) 2-pyrazoline and (iii) 1, 3-pyrazoline, 2pyrazoline is most attractive and important among all type of pyrazolines for frequent studies.

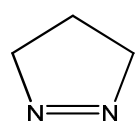

1- Pyrazoline<smiles>C1=NNCC1</smiles>

2- Pyrazoline<smiles>C1=CNNC1</smiles>

3- Pyrazoline
Fig. 1: Types of pyrazoline
Actually, pyrazolines are the reduced forms of pyrazoles, while pyrazolidine is a completely reduced form of pyrazole.

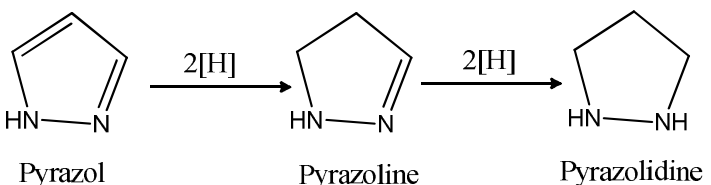

Fig. 2: Hydrogenation of pyrazole to pyrazoline then pyrazolidine

Pyrazoline derivatives have been found in natural products in the form of vitamins, alkaloids, and pigments.

Pyrazoline end products were stated to retain a number of evident pharmacological activities, antimoebic, antimicrobial, antibacterial, antidepressant, antitubercular, antifungal, antiviral, anticancer, anticonvulsant. Some of the modern drugs of the pyrazoline nucleus include Phenazone, Metamizole, Aminopyrine, Phenylbutazone, Sulfinpyrazone, Oxyphenbutazone and Celecoxib. The literature search was steered using accessible databases, including ScienceDirect, PubMed, Scopus and Google Scholar. The dissertations, thesis, books and technical reports were also combed. The objective of this review is to provide all the literature of approximately fifteen years.

\section{Antimicrobial activity of pyrazoline derivatives}

Chimenti et al. (2005) prepared N-substituted 3, 5-diphenyl pyrazoline derivatives and then screened for antibacterial activity. All pyrazoline derivatives displayed minute activity or no activity against different bacteria and fungus. The similar derivatives displayed a substantial activity against $H$. pylori strains. Between the synthesized derivatives, which containing the $\mathrm{N}$-acetyl group and methoxy group at position 4 on the phenyl ring exhibited the greatest potential against metronidazole resistant $H$. pylori strains at the $1-4 \mu \mathrm{g} / \mathrm{ml}[5]$.

Shivarama et al. (2005) reflux aryl furfurals with different acetophenones then condensate Aryl furyl propenones. Cyclocondensation provided 1H-pyrazoline derivatives and $\mathrm{N}$ phenylpyrazoline derivatives, respectively, when arylfuryl propenones react with hydrazine hydrate and phenylhydrazine. We 
found deliberated antibacterial activity of the new pyrazoline derivatives [6].<smiles>CC1C(N(C)CS(=O)(=O)O)C(=O)N(c2ccccc2)N1C</smiles>

Metamizole<smiles>Nc1nc2ncncc2[nH]1</smiles>

aminopurine<smiles>CCCCC1C(=O)N(c2ccccc2)N(c2ccccc2)C1=O</smiles><smiles>CC(=O)CCC1CN(c2ccc(O)cc2)N(c2ccccc2)C1=O</smiles><smiles>Cc1ccc(-c2cc(C(F)(F)F)nn2-c2ccc(S(N)(=O)=O)cc2)cc1</smiles>

Celecoxib

Fig. 3: Some of the modern drugs having pyrazoline nucleus<smiles>[R]c1ccc(C2CC(c3ccccc3)=NN2[Z7])cc1</smiles>

Fig. 4: N-substituted 3, 5-diphenyl pyrazoline derivatives

Ozdemir et al. (2007) synthesized 1-(4-aryl-2-thiazolyl)-3-(2thienyl)-5-aryl-2-pyrazoline derivatives from phenacyl bromides in ethanol. All manufactured derivatives evaluated against E. coli, $S$. typhimurium, $S$. aureus, $S$. faecalis, B. cereus, $A$. hydrophila, $C$. albicans, C. glabrata for antimicrobial activity [7].

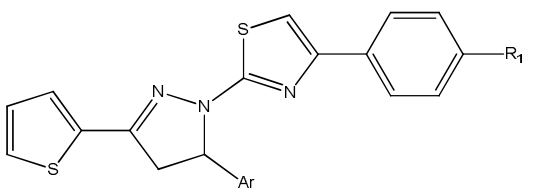

Fig. 5: Substituted 1-(4-aryl-2-thiazolyl)-3-(2-thienyl)-5-aryl-2pyrazoline
Kaplanciki et al. (2007) synthesized the substituted pyrazoline derivatives. For this, when phenacyl bromides react with different 3(2-thienyl)-5-aryl-1-thiocarbamoyl-2-pyrazolines in ethanol results 1-(4-aryl-2-thiazolyl)-3-(2-thienyl)-5-aryl-2-pyrazoline derivatives. The antimicrobial activity of synthesized compound was evaluated in contrast to $S$. typhimurium, E. coli, B. cereus, $A$. hydrophila, $L$. monocytogenes, $S$. aureus, C. albicans, and C. glabrata [8].

Kaplanciki et al. (2007) reported the newly prepared 1-(4-aryl-2thiazolyl)-3-(2-thienyl)-5-aryl-2-pyrazoline derivatives by substituted 3-(2-thienyl)-5-aryl-1-thiocarbamoyl-2-pyrazolines. The antimicrobial activity of synthesized pyrazoline derivatives was screened against bacterial strains E. coli, S. aureus, S. typhimurium, B. cereus, $L$. monocytogenes, A. hydrophila, C. albicans, and C. glabrata [9].

Shaharyar et al. (2007) synthesized the pyrazoline derivatives by 4 hydroxy-3-methylacetophenone condensed with different aromatic aldehydes in methanolic $\mathrm{KOH}$ results chalcones. These chalcones react with the hydrazine hydrate in ethanol to results pyrazoline derivatives. All synthesized derivatives were evaluated against Mycobacterium tuberculosis $\mathrm{H}_{37} \mathrm{Rv}$ for their anti-tubercular activity. The novel heterocyclic compound displayed favorable anti-tubercular activity against Mycobacterium tuberculosis drug-sensitive and drugresistant strains of Mycobacterium tuberculosis [10].<smiles>[R]C1CC(c2ccc(O)c(C)c2)=NN1</smiles>

Fig. 6: 4-hydroxy phenyl pyrazoline derivatives

Munawar et al. (2008) explained the quinolinyl chalcones react with phenyl hydrazine to obtain a series of 2-pyrazoline derivatives under both conventional and microwave-induced method. All synthesized compounds were evaluated for antimicrobial activity against bacteria S. aureus, S. typhii, E. coli, and Shigella dysentery. All synthesized derivatives have displayed antimicrobial activity. The compounds which containing a chloro group as a substituent has been more potent antimicrobial activity [11].<smiles>[R]c1ccc(C2CC(c3c(O)c4ccccc4n([R])c3=O)=NN2c2ccccc2)cc1</smiles>

Fig. 7: Quinolinyl 2-pyrazoline derivatives

Kiniet al. (2008) reacting isoniazid with substituted diaryl chalcones in $\mathrm{N}, \mathrm{N}$-DMF to synthesize the 1, 3, 5-trisubstituted-2-pyrazoline derivatives. All the synthesized derivatives screened for in vitro antimicrobial activity against $E$. coli, $P$. aeruginosa, B. subtilis, $S$. aureus and $A$. niger at different concentrations, compounds show significant antimicrobial activity [12].

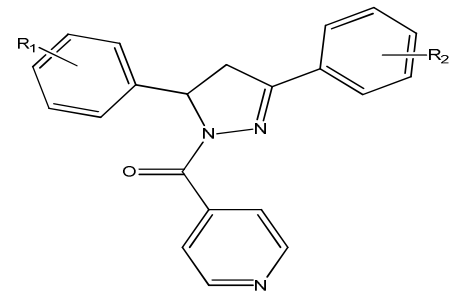

Fig. 8: 1, 3, 5-trisubstituted-2-pyrazoline 
Kini et al. (2008) reported when the isoniazid reflux with different substituted diaryl chalcones in N,N-dimethyl formamide at 120-140 - results 1,3,5-trisubstituted-2-pyrazolines. For antimicrobial activity, the synthesized compounds were screened against $B$. subtilis, S. aureus, P. aeruginosa, A. niger and E. coli. Also the quinolinyl chalcones react with phenyl hydrazine to obtain series of 2-pyrazolines under both conventional and microwave-induced warming method. All synthesized compounds were evaluated for antimicrobial activity against $S$. aureus, S. typhii, E. coli, and Shigella dysentery. All synthesized derivatives have displayed antimicrobial activity. The compounds containing chloro group as a substituent have been more potent antimicrobial activity [13]

Ramesh et al. (2009) prepared the chalcones of 2-acetyl thiophene reflux with phenylhydrazine hydrochloride in alkaline alcohol outcomes new pyrazoline derivatives. Some of these derivatives exhibited moderate to considerable antimicrobial activity. The results are showing that the compounds 1 and 2 showed significant antibacterial activity at conc. of $0.05-0.1 \mathrm{ml}$ concentration levels as compared through standard drug sparfloxacin. The other compounds 3, 4 and 5 displayed adequate activity [14].<smiles>[R]C1CC(c2cccs2)=NN1c1ccccc1</smiles>

Fig. 9: Thiophene pyrazoline derivatives

Manna et al. (2009) reported a series of 2-[1-(5,8Dihydroquinoxalino[2,3-b]indoloacetyl)-3-(1-benzofuran-2-yl)-4,5dihydro-1H-pyraz-ol-5-yl] phenyl derivatives which is synthesized by reacting the 2-(5,8-dihydro quinoxalino[2,3-b]indol-5-yl) acetohydrazide with (2E)-1-(1-benzofuran-2-yl)-4-phenylbut-2-en1-ones derivatives by microwave-assisted method. Some compounds were show decent antibacterial activity against $S$. aureus, $P$. aeruginosa and E. coli, compared with standard drugs sparfloxacin and norfloxacin at the conc. of $10 \mu \mathrm{g} / \mathrm{ml}$ [15].

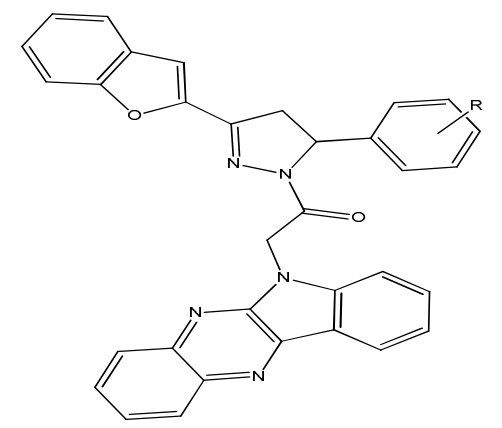

Fig. 8: 2-[1-(5, 8-Dihydroquinoxalino $[2,3-b]$ indoloacetyl)-3-(1benzofuran-2-yl)-4,5-dihydro-1H-pyrazol-5-yl] phenyl derivatives

Chawla et al. (2010) synthesized substituted [3-(4-phenyl)-5phenyl-4, 5-dihydropyrazol-1-yl](pyridine-4-yl)methanone and 3substituted phenyl-5-substituted phenyl-4,5-dihydro-pyrazole-1carbothioamides by microwave techniques. All the derivatives were evaluated for antibacterial activity against B. subtilis, E. coli, $P$. aeruginosa and $S$. aureus and antifungal activity beside C. albicans, $A$. niger. The derivatives showed adequate antibacterial and respectable antifungal actions [16].

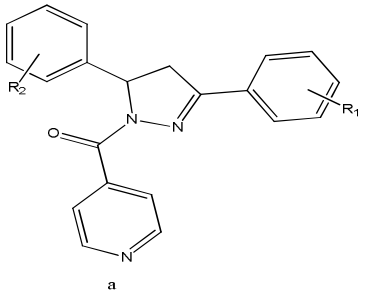

a

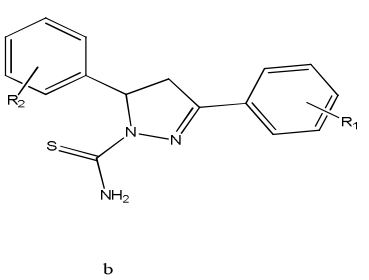

Fig. 11: (a) substituted [3-(4-phenyl)-5-phenyl-4,5-dihydropyrazol1-yl](pyridine-4-yl)methanones, (b) 3-substituted phenyl-5substituted phenyl-4,5-dihydro-pyrazole-1-carbothioamides
Sivakumar et al. (2010) manufactured novel 1, 3, 5-triphenyl-2-pyrazoline derivatives and two-fold dilution method using resazurin (indicator dye) is used for screening of antibacterial activity against $S$. aureus, $S$. typhi, $B$. subtilis, E. aerogenes, $P$. aeruginosa and Proteus vulgaris by SAR study concluded that 1,3,5triphenyl-2-pyrazoline derivatives. Chlorine replacement in the ring A, is the positive discrimination for antibacterial activity. Hydrophilic/lipophilic balance of the derivatives are important parameters [17].

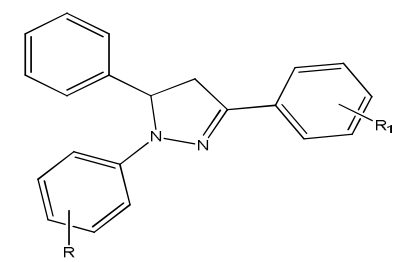

Fig. 12: Novel 1, 3, 5-triphenyl-2-pyrazoline derivatives

Venkataraman et al. (2010) synthesized some new pyrazoline derivatives from Chalcones. Which may be synthesized by different acetophenones react with different benzaldehydes to give chalcone, which on condensed with hydrazine hydrate in ethanol to acquire pyrazoline derivatives. All derivatives were tested for in vitro antibacterial and anti-inflammatory activities. All synthesized derivatives were confirmed activity against $S$. aureus, B. subtilis, $E$. coli, $P$. aureginosa. Some of the new derivatives exhibited promising anti-inflammatory activities [18].

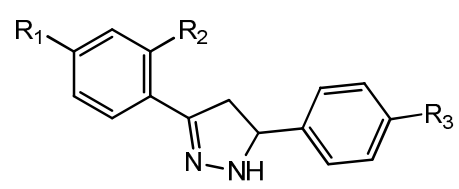

Fig. 13: 3, 5 diphenyl pyrazoline

Sakthinathan et al. (2012), reported that when 2-naphthyl chalcones in the presence of phenylhydrazine hydrochloride and sodium acetate by the cyclization reaction results 2-naphthyl pyrazoline derivatives. 2-naphthyl pyrazoline derivatives subjected for antimicrobial activity [19].

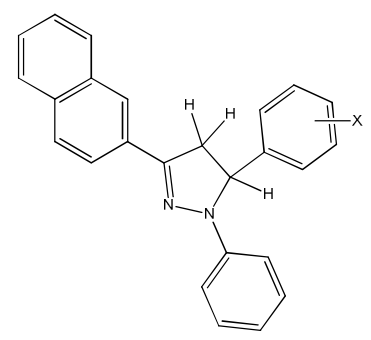

Fig. 14: 2-naphthyl pyrazoline derivatives 
Shah et al. (2012) synthesized 4-(4-hydroxyphenyl)-3-chloro-1-\{4-[5(substituted phenyl)-1-phenyl-4,5-dihydro-pyrazol-3-yl]phenyl\} azetidin-2-one by 3-chloro-1-\{4-[3-(substituted-phenyl)prop-2-enoyl] phenyl\}-4-(4-hydroxyphenyl) azetidin-2-one (0.01M) and phenylhydrazine $(0.01 \mathrm{M})$ in presence of glacial acetic acid. All the synthesized derivatives were screened for antimicrobial activity through broth dilution method. The compound containing chloro substitution in the phenyl ring has shown respectable antibacterial activity [20].

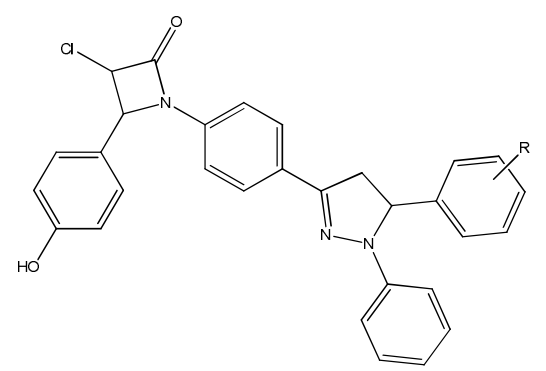

Fig. 15: 4-(4-hydroxyphenyl)-3-chloro-1-\{4-[5-(substituted phenyl)-1-phenyl-4,5-dihydro-pyrazol-3-yl]phenyl\} azetidin-2-one

Rani et al.(2012) prepared alkoxy a series of N-substituted cyclized pyrazoline equivalents [5-(furan-2-yl)-3-[2-(alkoxy) phenyl]-4, 5dihydro-1H-pyrazole-1-carbothioamide by cyclization of [1-[2(alkoxy) phenyl]-5-(furan-2-yl)-prop-2-en-1-one] chalcone with thiosemicarbazide in the presence of alkaline ethanol. By the disc diffusion method, in vitro antibacterial activity of newly prepared derivatives were screened and the minimum inhibitory concentration (MIC) was calculated against microorganism such as A. hydrophila, $Y$. enterocolitica, L. monocytogenes, and S. aureus. Between all the compounds, alkoxy [5-(furan-2-yl)-2(benzyloxy)phenyl]-4,5-dihydro-1H-pyrazole-1-carbothioamide and 5-(furan-2-yl)-1-[2-(naphthalen-2-ylmethoxy) phenyl]-4,5-dihydro1H-pyrazole-1-carbothioamide exhibited the greatest favorable antibacterial activity as compared to standard gentamycin and tetracycline [21].

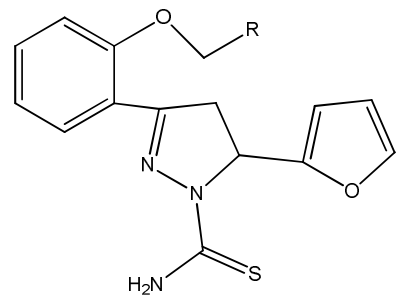

Fig. 16: N-substituted cyclized pyrazoline

Dipankar et al. (2012) synthesized twelve 2-pyrazoline derivatives and evaluated the antimicrobial activity against $A$. niger and $S$. aureus. For this, 2 types of acetophenone reacted with 3 types of substituted benzimidazole derivatives to acquire 6 chalcone derivatives, which undergo condensation and cyclisation with isoniazid and 1-(2-napthyloxy acetate) hydrazine to acquire the 2pyrazoline derivatives. The synthesized derivatives were established to have good antimicrobial activity at the conc. of $20-70 \mu \mathrm{g} / \mathrm{ml}[22]$.

S Y Hassan (2013) has reported a series of new 2-pyrazoline derivative carrying benzene sulfonamide moieties were produced by reaction of suitable chalcones with 4-hydrazinyl benzene sulfonamide $\mathrm{HCl}$. Besides the reaction of chalcones with the hydrazine derivative produces pyrazole compounds. All the synthesized compounds have been categorized by physical and spectral fig. Antimicrobial activity of synthesized compounds were tested against $S$. aureus, P. aeruginosa, E. coli and antifungal activity in contrast to $C$. albicans must been considered by the nutrient agar and saboraud dextrose agar diffusion procedures [23].<smiles>CC1=NN(C(N)=S)C(c2cc3c([nH]2)CC(C)(C)CC3=O)C1</smiles><smiles>CC1(C)CC(=O)c2cc(C3CC([Al])=NN3)[nH]c2C1</smiles>

Fig. 17: Pyrazoline derivative carrying benzene sulfonamide

Nosrat et al. (2013) prepared novel 2-(3, 5-diphenyl-4, 5-dihydro$1 H$-pyrazol-1-yl)-4-phenylthiazoles via cyclo-condensation of several chalcones, phenacyl bromide and thiosemicarbazide. The reaction was efficiently conducted under reflux through a few drops of $\mathrm{HCl}$ in Ethanol. The antibacterial action of compounds was observed, Certain compounds display satisfactory actions [24].<smiles>[M]C1=NC2=NN(c3nc(-c4ccccc4)cs3)c3ccc([R])cc3OC12</smiles>

Fig. 18: Substituted 2-(3, 5-diphenyl-4, 5-dihydro-1H-pyrazol-1yl)-4-phenylthiazoles

Rani et al. (2014) synthesized the sequence of new pyrazoline derivative as well as antimicrobial activity of certain pyrazoline derivatives and the structures were identified by spectral fig. Certain derivatives exhibited analogous results after tested against $Y$. enterocolitica, A. hydrophila, S. aureus and L. monocytogene. Some derivatives display additional action as compared to the standard drugs tetracycline $(30 \mu \mathrm{g})$ and gentamicin $(10 \mu \mathrm{g})$ [25].

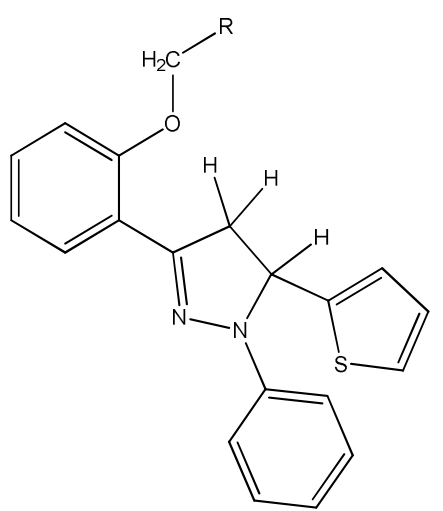

Fig. 19: Tricyclic pyrazoline derivative

Vidya et al. (2014) have reported a modest, well-organized method for the synthesis of novel 2-pyrazolines. In this, the chalcones condense with hydrazine hydrate/isoniazid/tolylsulfonyl hydrazide results pyrazoline derivatives. The synthesized derivatives have been tested for antimicrobial activity in several types of microorganisms. An important level of activity was noticed [26]. 


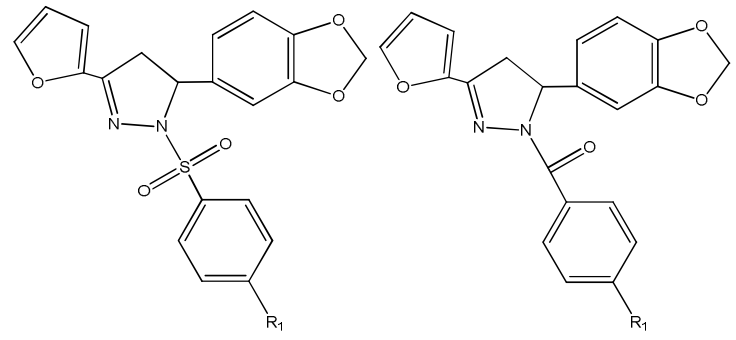

Fig. 20: Novel 2-pyrazolines

Desai et al. (2014) synthesized quinazolinyl-2-pyrazoline derivatives series and screened for the in vitro antibacterial potency against gram-positive strains ( $S$. Aureus, B. Subtilis) and gram negative strains (E. coli, P. aeroginosa) comparing with the standard drugs ampicillin, amoxycillin and penicillin and antifungal activity against C. Albicans and C. Krusei. as compared with fluconazole by disc diffusion method [27].<smiles></smiles>

Fig. 21: Quinazolinyl 2-pyrazolines
Ishwar Bhat et al. (2014) were reported that the reactions of chalcones with aryloxy acetyl hydrazines yield $(70-80 \%) 1,3,5$ substituted pyrazoline derivatives in the presence of glacial acetic acid. Synthesized compounds were screened for antibacterial, antifungal and antitubercular activity studies. Synthesized compounds showed significant activity against ampicillin and moderate to significant antifungal activity against griseofulvin. Antibacterial activity studies revels that good antitubercular activities against isoniazid as a standard drug [28].

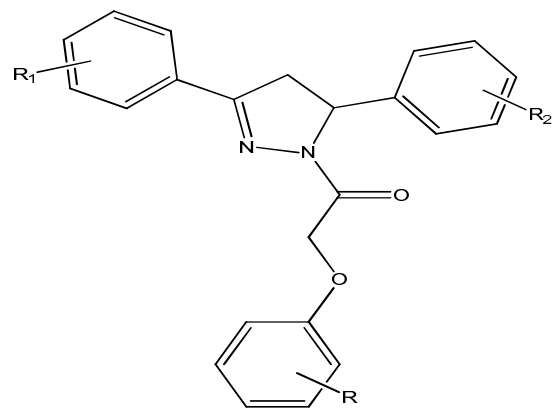

Fig. 22: 1, 3, 5 Substituted pyrazoline derivatives

Viveka et al. (2015) reported substituted pyrazole skeleton linked newly synthesis of pyrazolines. The reaction was accomplished by a multistep procedure. They were tested these novel derivatives for antibacterial, analgesic and anti-inflammatory activities. The derivatives which contain halogen atom at phenyl ring on $3^{\text {rd }}$ position of the pyrazoline ring were establish to be active in contrast to bacteria at the conc. of $0.2-0.4 \mathrm{mg} / \mathrm{ml}$. Derivatives those containing $N$-propionyl pyrazolyl-pyrazoline recognized as, having dual activity, anti-inflammatory and antibacterial activity [29].

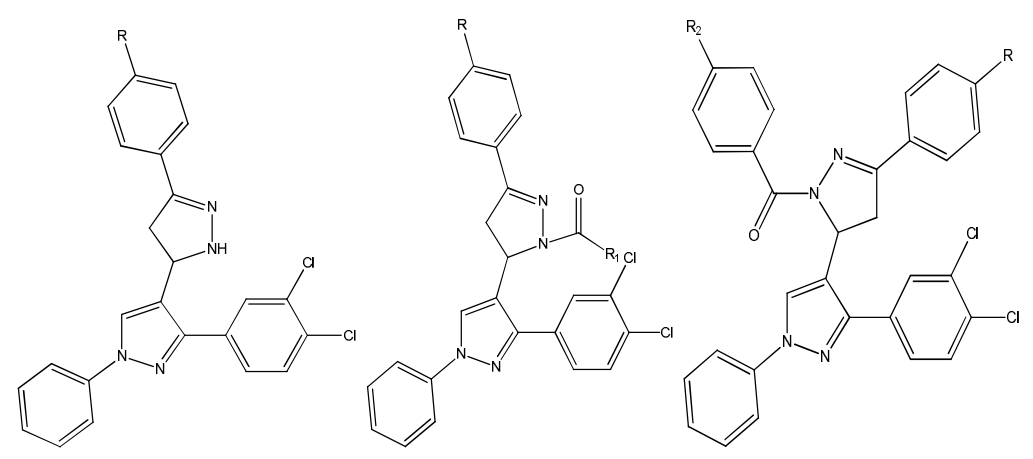

Fig. 23: Newly synthesis of pyrazolines

Alam et al. (2015) synthesized a series of pyrazoline derivatives and structural identification done by ${ }^{1} \mathrm{H}$ NMR, [13]C NMR, IR and Mass spectrum. All newly synthesized derivatives were evaluated against two bacterial and four fungal strain (C. Albicans, A. Flavus, A. Fumigatus, A. versicola) at the conc. of $12.5 \mu \mathrm{g} / \mathrm{ml}$ compared with standard drug fluconazole. All compounds display moderate to potent antifungal activity [30].

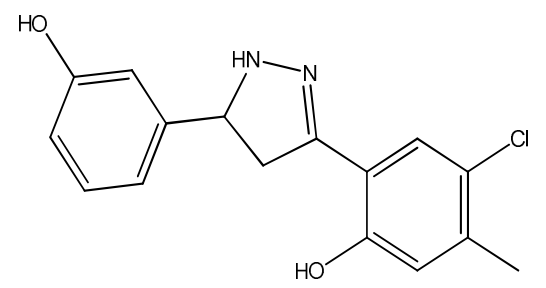

Fig. 24: Disubstituted pyrazoline derivatives
Parajuli et al. (2015) reported that the reaction of chalcones with phenylhydrazine results a novel 3-phenyl-5-(4-dimethylaminophenyl)1-phenyl-pyrazolone. The synthesized compounds were tested against $S$. faecalis, $S$. aureus and E. coli for their antibacterial activity by disc diffusion method. The researcher concluded on the basis of antibacterial evaluation data that the synthesized new compounds showed sufficient antibacterial activity towards $S$. aureus [31].

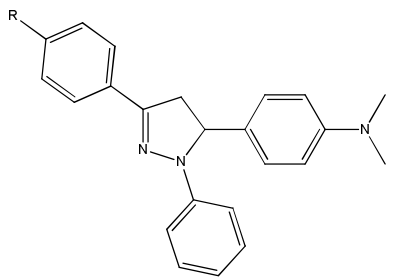

Fig. 25: Novel 3-phenyl-5-(4-dimethylaminophenyl)-1-phenylpyrazoline 
Sulthana et al. (2015) reported a research paper on design and synthesis a new series of thiophene and benzodioxole appended thiazolyl-pyrazoline derivatives by the microwave-assisted method and screened for antimicrobial potency against different bacteria and fungi. Few compounds show good antimicrobial potency [32].

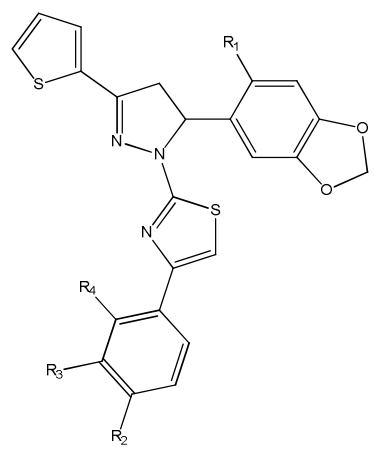

Fig. 26: Thiazolyl-pyrazoline derivatives

Alnitop et al. (2015) synthesized Thiazolyl-pyrazoline derivatives and subjected to evaluate for antifungal potency against the pathogenic yeast and mold by broth microdilution method as compared to standard drug ketoconazole at the MIC conc. of $250 \mu \mathrm{g} / \mathrm{ml}$ [33].

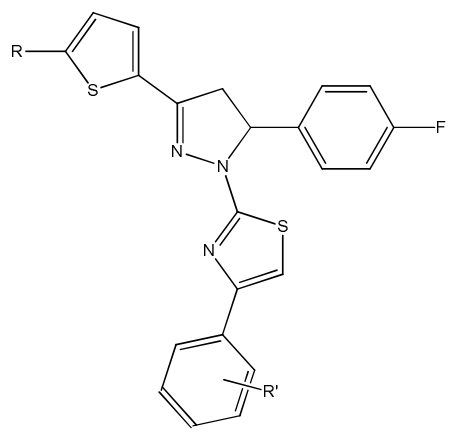

Fig. 27: Thiazolyl-pyrazoline derivatives

Indorkar et al. (2015) published a research paper on newly synthesized 1-acetyl/acetophenyl-3-(4-nitrophenyl)-5-(substituted phenyl) pyrazoline derivative. They tested them for antimicrobial potency against the pathogenic bacterial strains such as B. subtilis, $E$. coli, K. pneumonia and S. aureus. Further tested against a pathogenic panel of fungal strains like A. niger, A. flavus, T. viride and C. albicans for antifungal activity. On the basis of obtained results, it is concluded that almost all the synthesized new pyrazoline derivatives had displayed variable growth inhibitory effects [34].

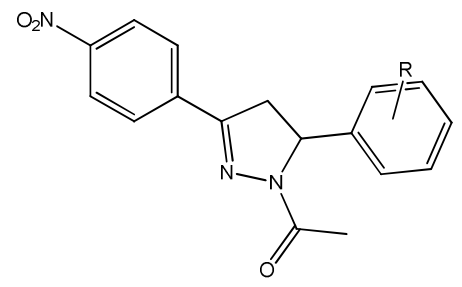

Fig. 28: 1-acetyl/acetophenyl-3-(4-nitrophenyl)-5-(substituted phenyl) pyrazoline derivative

Karangiya et al. (2016) reported a series of newly synthesized 3(Aryl)-5-[4-(2,4-Dichlorophenylmethoxy)-3-methoxyphenyl]-4,5- dihydro pyrazoline and 3-(Aryl)-5-[4-(2,4-Dichlorophenylmethoxy)-3methoxyphenyl]-4,5-dihydroacetyl pyrazoline derivatives. The chalcones were synthesized by Claisen-Schmidt condensation. The synthesized compounds were subjected for antimicrobial activity [35].

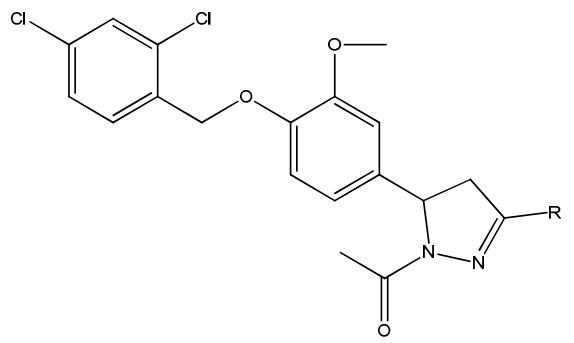

Fig. 29: 3-(Aryl)-5-[4-(2,4-Dichlorophenylmethoxy)-3methoxyphenyl]-4,5-dihydro pyrazoline

Ahmed et al. (2016) reported the synthesis of two series of pyrazoline derivatives beginning from p-acetamidophenol (paracetamol) and screened for antimicrobial activity. Chalcones were prepared by reacting 3-acetyl-4-hydroxyphenyl acetamide with different aromatic aldehydes. These chalcones were further reacted with phenylhydrazine and isoniazid to get phenylpyrazolines and isoniazid-pyrazolines. New pyrazoline derivatives displayed important antibacterial potency against E. coli, S. aureus, and $P$. aeruginosaas compared using the standard antibiotic ciprofloxacin. In the conclusion found that some derivatives possesses powerful antibacterial activity against $S$. aureus, $P$. aeruginosa and at the conc. of $3.12 \mathrm{mg} / \mathrm{ml}[36]$.<smiles>CC(=O)Nc1ccc(O)c(C2=NN(c3ccccc3)C(c3ccccc3)C2)c1</smiles>

(a)

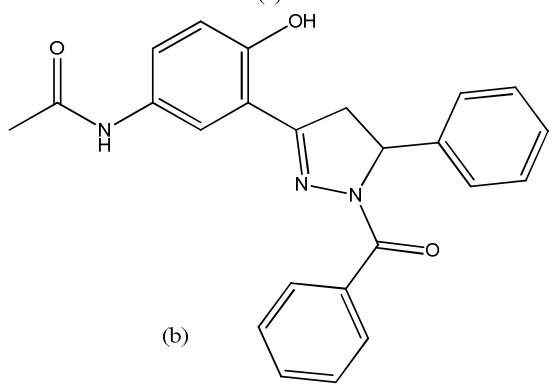

Fig. 30: (a) phenyl-pyrazolines and (b) isoniazid-pyrazolines

Muneera et al. (2016) synthesized biologically active pyrazoline derivatives by the reaction of imidazole-2-carboxaldehyde with 1acetyl-2-hydroxynaphthalene using Claisen-Schmidt condensation reaction. Metal acetates ligands further formed from the metal complexes with $\mathrm{Ni}(\mathrm{II}), \mathrm{Co}(\mathrm{II}), \mathrm{Cu}(\mathrm{II})$ and $\mathrm{Zn}(\mathrm{II})$ metals, respectively. All metal complexes structures were analytically confirmed by IR, NMR, Mass, ESR spectroscopy and elemental analysis. All synthesized derivatives were screened against bacterial strains $E$. coli, S. aureus, K. pneumoniae, Proteus mirabilis and S. typhii as compared to the standard drug streptomycin. All compounds also were estimated for in vitro antimycobacterial activity against Mycobacterium tuberculosis [37]. 
<smiles>CON(O)Oc1ccc2ccccc2c1C1=NN(c2ccccc2)C(C2=CCCN2)C1</smiles>

Fig. 31: Metal complex of pyrazoline derivatives

Sid et al. (2016) synthesized the 1-formyl-3-phenyl-5-(4isopropylphenyl)-2-pyrazoline as pure crystal and their structure was confirmed by spectral analysis like FT-IR, NMR, XRD. Compound was screened for anti-microbial activity and the compound shows favorable activity [38].<smiles>CC(C)c1ccc(C2CC(c3ccccc3)=NN2C=O)cc1</smiles>

Fig. 32: 1-formyl-3-phenyl-5-(4-isopropylphenyl)-2-pyrazoline

Patel et al. (2016) reported the synthesis of 2-pyrazolines from chalcones by conventional and microwave-assisted techniques. All new compounds have been confirmed by The ${ }^{1}$ HNMR,[13]C NMR, IR and Mass spectroscopy. All the synthesized compounds were screened for antibacterial potency against gram-positive bacteira $(S$. Aureus, S. Pyrogens) at the conc. of $200 \mu \mathrm{g} / \mathrm{ml}$, and gram-negative bacteria (P. Aeruginosa, E. coli) at the conc. of $500 \mu \mathrm{g} / \mathrm{ml}$ as compared to standard ampicillin and for the antifungal potency against A. niger, C. Albicans, A. Clavatus at conc. of 250,500, 1000 $\mu \mathrm{g} / \mathrm{ml}$ as compared with the standard griseofulvin and nystatin [39].

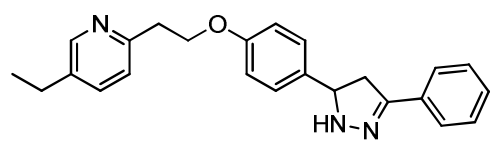

Fig. 33: 2-pyrazolines derivatives

Shamsuzzaman et al. (2016) synthesized a new steroidal pyrazoline derivatives series by the reaction between $\alpha, \beta$ unsaturated ketone in DMSO and 2,4 dinitrophenyl hydrazine with few drops of acetic acid. The structures of synthesized new derivatives were elucidated by ${ }^{1}$ HNMR, [13]C NMR, IR, Mass spectra and analytical data. The synthesized compound were evaluated for antimicrobial potency against Coryne bacterium xerosis, S. epidermidis, E. coli by disc diffusion method as compared to the gentamicin and anti fungal activity against $M$. azygosporus, A. niger $C$. purpurea, as compared with the standard drug ketoconazole [40].

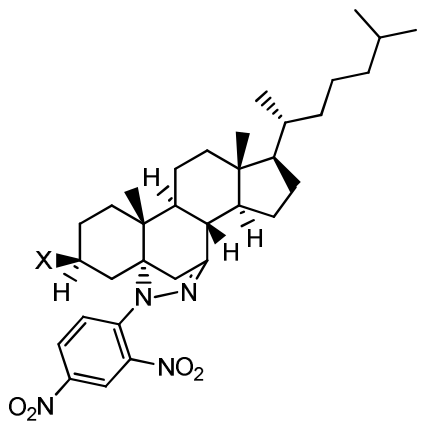

Fig. 34: New steroidal pyrazoline derivatives
Karad et al. (2016) synthesized a novel morpholino quinoline based conjugates with pyrazoline moiety by microwave irradiation technique. The new compounds were evaluated for in vitro antibacterial activity against pathogenic strains of bacteria and fungi comparing with standard drugs ampicillin, chloramphenicol, ciprofloxacin and griseofulvin [41].

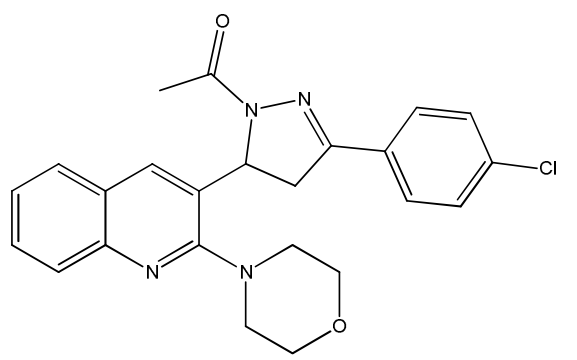

Fig. 35: Morpholino quinoline based pyrazoline

Tejas J. Shah et al. (2016) prepared a series of 3-[3'-(2",4"-dichloro-5"fluorophenyl)-5'-(2"-furyl)-4', 5' $\quad$ '-dihydro-1H-pyrazol-1'-yl]-5substituted phenyl-2-pyrazolines and 1-Nitroso-3-[3'-(2",4"-dichloro-5"fluorophenyl)-5'-(2"-furyl)-4',5'-dihydro-1H-pyrazol-1'-yl]-5-substituted phenyl-2-pyrazolines. Some compounds exhibited antimicrobial activity against some Gram (+) and Gram (-) bacteria [42].

Desai et al. (2017) synthesized few novel derivatives of (5-(2chloroquine in-3-yl)-3-(aryl)-4, 5-dihydro-1H-pyrazol-1-yl)(pyridin4-yl) methanones moieties embedded in different biologically active heterocyclic compounds e. g. pyrazoline quinoline and pyridine derivatives. Reported compounds were analytically determined by spectrometric methods like IR, ${ }^{1} \mathrm{H}$ NMR, [13]C NMR, Mass spectra. These compounds were screened for antimicrobial activity on four strains of bacteria (S. aureus, S. pyogenes, E. coli, P. aeruginosa) and three strains of fungi (C. albicans, A. niger, A. clavatus) using griseofulvin and ampicillin as the standard drugs [43].<smiles>O=C(c1ccccc1)N1N=C(c2ccccc2)CC1c1cc2ccccc2nc1Cl</smiles>

Fig. 36: (5-(2-chloroquinolin-3-yl)-3-(aryl)-4,5-dihydro-1Hpyrazol-1-yl)(pyridin-4-yl) pyrazoline

Mishra et al. (2017) prepared a novel series of 1, 3, 5-trisubstituted pyrazoline derivatives by reacting chalcones and nicotinic acid hydrazide in two steps. $1^{\text {st }}$ step is the preparation of chalcones by treatment of substituted benzaldehyde with 4-hydroxy acetophenone by Claisen-Schimidt Condensation. $2^{\text {nd }}$ step is the reflux condensation of isoniazid with chalcones in alkaline ethanol results in various pyrazoline derivatives. The newly manufactured compounds were structurally confirmed by spectral analysis (IR, ${ }^{1} \mathrm{H}$ NMR,[13] ${ }^{\mathrm{C}} \mathrm{NMR}$ ) and elemental analysis. The pyrazoline derivatives were screened for antibacterial and antimalarial activity as compared to the standard drugs ciprofloxacin. The compounds were tested on bacteria S. aureus, B. Subtilis, E. coli and P. aeruginosa, and fungus against A. niger at the MIC- $3.25 \mu \mathrm{g} / \mathrm{ml}$ and C. albicans at MIC$6.5 \mu \mathrm{g} / \mathrm{ml}$ as compared with the standard drug fluconazole. For antimalarial activity, the pyrazoline derivatives were tested against 
chloroquine-sensitive and chloroquine-resistant $P$. falciparum strains [44].

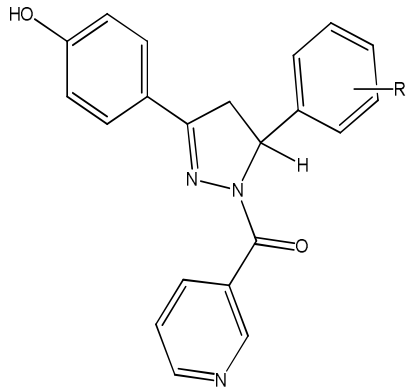

Fig. 37: Novel series of 1, 3, 5-trisubstituted pyrazolines

Rashmi et al. (2017) synthesized a novel series of four 1thiocarbamoyl-3, 5-diphenyl-2-pyrazoline derivatives by microwave irradiation method in a modified domestic microwave oven. The synthesized new compounds were evaluated for their antibacterial activity by well diffusion method against two gram-positive strains (Staphylococcus aureus MRSA, Pseudomonas spp.) and two gramnegative strains (Escherichia coli, Bacillus cereus). The synthesized compounds 1-thiocarbamoyl-3,5-diphenyl-2-pyrazoline and 1thiocarbamoyl-3-(4'-chlorophenyl)-5-(4-chlorophenyl)-2-pyrazoline showed potent activity against both the gram-positive strains Staphylococcus aureus MRSA and Pseudomonas spp [45].

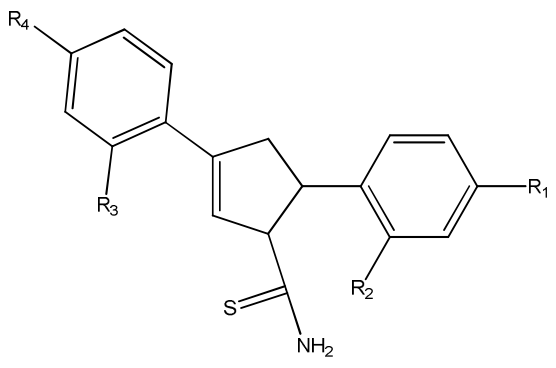

Fig. 38: 1-thiocarbamoyl-3,5-diphenyl-2-pyrazoline derivatives

Sadashiva et al. (2017) published a research paper on the design and synthesis of 2, 4 disubstituted 1,3-thiazoles linked pyrazoline moiety series. The structural elucidation of synthesized new compounds was done by UV-Vis, IR, NMR, Mass spectroscopy and elemental analysis. The new compounds were screened for in vitro, antimicrobial activity against some pathogenic microbial strains [46].

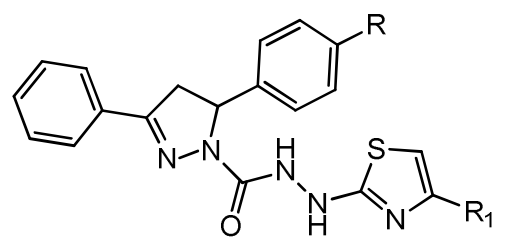

Fig. 39: 2, 4 disubstituted 1,3-thiazoles linked pyrazolines

R Umadevi (2017) synthesized some novel pyrazoline derivatives from chalcones which are prepared by the treating 2-acetyl-5bromothiophene with various aromatic aldehydes. These chalcones further condensate with phenylhydrazine HCL, pyridine as a catalyst results 3-(5-bromo thiophene-2-yl)1-phenyl-1-pyrazole derivatives. The synthesized compounds have been identified by their melting point, TLC, IR and NMR spectral data. All the synthesized compounds have been evaluated for antibacterial potential against gram-positive bacterial strains, B. subtillis and B. pumilus and gram-negative bacterial strains $E$. coli and $P$. vulgaris and antifungal activity against fungal strains, A. niger and p. crysogenium [47].<smiles>[R]C1CC(c2ccc(Br)s2)=NN1c1ccccc1</smiles>

Fig. 40: 3-(5-bromo thiophene-2-yl)1-phenyl-1-pyrazole derivatives

Kumarswami et al. (2017) synthesized some new pyrazoline derivatives from chalcones and the hydrazine hydrate in alkaline ethanol. The chalcones have been prepared by the reaction of acetophenone with various benzaldehyde. The synthesized new compounds were characterized by NMR, IR and mass spectroscopy. All the compounds were evaluated for antibacterial activity against gram-positive strains (S. Aureus, B. Subtilis) and gram negative strains (E. coli, K. Pneuminoae) at suitable conc. as compared to standard drug ciprofloxacin. All the compounds showed moderate to potent antibacterial activity [48].

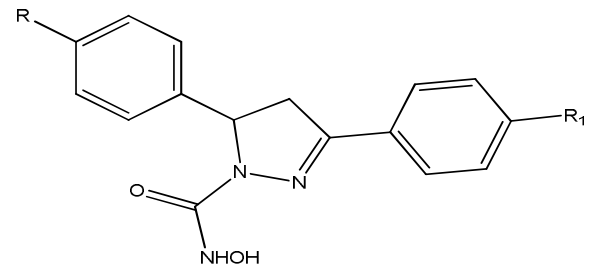

Fig. 41: New pyrazoline derivatives

Yusuf et al. (2017) synthesized a series of bispyrazolines from the cyclization of bischalcone with phenylhydrazine by reflux in dry acidic ethanol medium. According to Claisen-Schmidt condensation reaction, chalcone obtained by reacting p-hydroxy acetophenone with 2-furfuraldehyde. The bischalcones and bispyrazolines structures were confirmed by ${ }^{1} \mathrm{H}$ NMR, ${ }^{13} \mathrm{C}$ NMR, IR and Mass spectroscopy. Newly synthesized compounds were screened for their antimicrobial potency against seven strains of bacteria (E. coli, $K$. pneumonia, P. fluorescens, S. aureus, $P$. aeruginosa B. subtilis, $S$. pyrogen,) and five strains of fungus (A. sclerotium, Penicillium glabrum, A. niger, A. janus, Fusarium oxysporum) by using serial tube dilution method as compared to the standard drug amoxicillin and fluconazole [49].

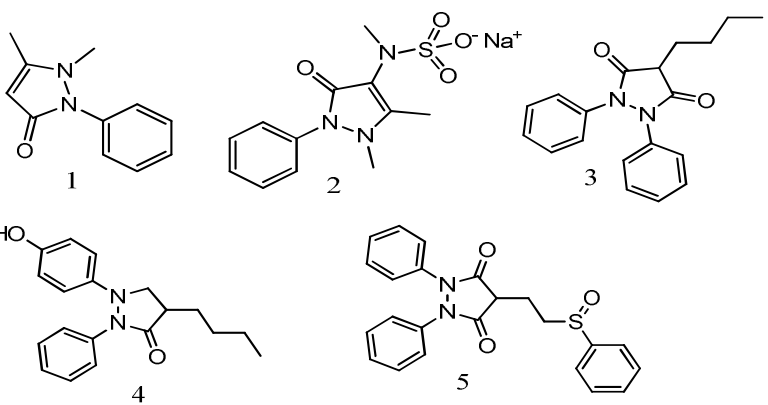

Fig. 42: Bispyrazolines

Burmidza et al. (2018) synthesized a series of ferrocenyl ketones by the reaction of ferrocene with substituted acryloyl chlorides. The reaction of ferrocenyl ketones with hydrazine in acidic medium prepares new pyrazoline derivatives. 12 strains of microbes 
(bacteria and fungi) were taken for antimicrobial activities of synthesized compounds as compared to standard drugs streptomycin and ketoconazole at the MIC conc. from 0.039$0.312 \mathrm{mg} / \mathrm{ml}[50]$.

Siliveri et al. (2019) reported the design and synthesis of pyrazoline incorporated 1,2,3 triazole benzene sulphonamides and all the synthesized compounds were characterized by FT IR, HNMR, ${ }^{13} \mathrm{CNMR}$ and Mass spectra. The synthesized compounds were evaluated for cytotoxic activity through using 3-(4, 5dimethylthiazol-2-yl)-2,5-diphenyltetrazolium bromide (MTT) assay and anti-gout activity by potassium oxonate induced assay [51].

Asad et al. (2020) synthesized a series of N-propionyl 2-pyrazolines from the chalcones by reacting propionic acid with hydrazine hydrate. The atomic structure of new pyrazoline derivatives were confirmed by FT-IR, NMR spectroscopy, crystal structure, X-ray diffraction techniques. All new compounds were evaluated for antibacterial activity against gram-positive bacterial strain ( $B$. Subtilis, S. Aureus) and gram-negative bacterial strain (E. Coli, P. Peli). All new compounds display significant activity against bacteria [52].<smiles>[R]C1=NN(C(=O)CC)C([R2])C1</smiles>

Fig. 43: N-propionyl 2-pyrazolines

\section{CONCLUSION}

The objective of this review is to provide a platform for researcher, academician, chemist and industrialists to have all the information regarding the antimicrobial activity of pyrazoline. Various synthetic routes were discussed with its chemistry. The literature eliciting the antimicrobial activity were discussed. As the literature shows that there is always demand of novel antimicrobial agents due to the pathogen resistance. So, this literature would be fruitful to the society as well. This would provide the researcher a lead that they may come with a new and potent pyrazoline bearing derivative.

\section{ACKNOWLEDGMENT}

The authors are thankful to the Laxmibai sahuji college of Pharmacy, Jabalpur (M. P.) for providing financial assistance.

\section{AUTHORS CONTRIBUTIONS}

The complete review work was suggested and designed by Saras Kumar Jain. Literature collection and written works were carried out by R Singhal.

\section{CONFLICT OF INTERESTS}

Authors declare no conflict of interest.

\section{REFERENCES}

1. Olczak KD, Daszkiewicz M, Slawinska K, Baginska DB, Gozdowski D, Daszkiewicz P. Bacteria and Candida yeasts in inflammations of the oral mucosa in children with secondary immunodeficiency. J Oral Path Med 2012;41:568-76.

2. Danishuddin M, Kaushal L, Hassan BM, Khan AU. AMDD: antimicrobial drug database. Genomics Proteomics Bioinf 2012;10:360-3.

3. Alvarez MA, Debattista NB, Pappano NB. Antimicrobial activity and synergism of some substituted flavonoids. Folia Microbiol 2008;53:23-8.

4. Abunada NM, Hassaneen HM, Kandile NG, Miqdad OA. Synthesis and biological activity of some new pyrazoline and pyrrolo $[3,4-$ c]pyrazole-4,6-dione derivatives: reaction of nitrilimines with some dipolarophiles. Molecules 2008;41:1011-24.

5. Chimenti F, Bizzarri B, Manna F. Synthesis and in vitro selective anti-Helicobacter pyloriactivity of pyrazoline derivatives. Bioorg Med Chem Lett 2005;15:603-7.

6. Shivarama B, Akberali HM, Shivananda MK. Studies on arylfuran derivatives: part X. Synthesis and antibacterial properties of arylfuryl- $\Delta^{2}$-pyrazolines. Farmacology 2005;5:256-63.

7. Ozdemir A, Zitouni GT, Kaplancıki ZA, Revial G, Güven K. Synthesis and antimicrobial activity of 1-(4-aryl-2-thiazolyl)-3(2-thienyl)-5-aryl-2-pyrazoline derivatives. Eur J Med Chem 2007;42:403-9.

8. Kaplancıkli ZA, Zitouni GT, Özdemir A, Gilbert RG, Güven K. Synthesis and antimicrobial activity of some thiazolylpyrazoline derivatives. Phosphorus Sulfur Silicon Related Elements 2007;182:4:749-64.

9. Kaplanciki ZA, Zitouni GT, Ahmet A, Revial G. Synthesis and antimicrobial activity of some thiazolyl-pyrazoline derivatives. Phosphorus Sulfur Silicon Related Elements 2007;182:202-8.

10. Shaharyar M, Siddiqui AA, Ali MA. Synthesis and antimycobacterial activity of novel heterocycles. J Serb Chem Soc 2007;72:5-11.

11. Munawar MA, Azad M, Athar M, Paul W. Groundwater synthesis and antimicrobial activity of quinoline-based 2-pyrazolines. Chem Papers 2008;62:288-93.

12. Kini S, Gandhi AM. Novel 2-Pyrazoline derivatives as potential antibacterial and antifungal agents. Indian J Pharm Sci 2008;70:105-8.

13. Kini S, Gandhi AM. Novel 2-pyrazoline derivatives as potential antibacterial and antifungal agents. Indian J Pharm Sci 2008;70:105-8.

14. Ramesh B, Babitha S, Prasad YR. Synthesis and antimicrobial activity of some new 2-pyrazoline derivatives. Int J Chem Sci 2009;7:2572-6.

15. Manna K, Agrawal YK. Microwave-assisted synthesis of new indophenazine 1,3,5-trisubstruted pyrazoline derivatives of benzofuran and their antimicrobial activity. Bioorg Med Chem Lett 2009;19:2688-92.

16. Chawla R, Sahoo U, Arora A, Sharma PC, Radhakrishnan V. Microwave assisted synthesis of some novel 2-pyrazoline derivatives as possible antimicrobial agents. Acta Polo Pharm Drug Res 2010;67:55-61.

17. Sivakumar PM, Ganesan S, Veluchamy P, Doble M. Novel chalcones and 1, 3, 5-triphenyl-2-pyrazoline derivatives as antibacterial agents. Chem Bio Drug Des 2010;76:407-11.

18. Venkataraman S, Jain S, Shah K, Upmanyu N. Synthesis and biological activity of some novel pyrazolines. Acta Polo Pharma Drug Res 2010;67:361-6.

19. Sakthinathan SP, Vanangamudi G, Thirunarayanan G. Synthesis, spectral studies and antimicrobial activities of some 2-naphthyl pyrazoline derivatives. Spectrochim Acta Part A 2012;95:693700.

20. Shah SS, Patel PS. Synthesis and biological activity of some novel phenyl pyrazoline derivatives. Chem Sci Trans 2012;1:632-7.

21. Rani M, Yusuf $M$, Khan SA. Synthesis and in the vitroantibacterial activity of [5-(furan-2-yl)-phenyl]-4,5carbothioamide-pyrazolines. J Saudi Chem Soc 2012;16:431-6.

22. Dipankar B, Paneerselvam P, Asish B. Synthesis, characterization and antimicrobial activities of some 2pyrazoline derivatives. Asian J Pharm Clin Res 2012;5:42-6.

23. Hassan SY. Synthesis, antibacterial and antifungal activity of some new pyrazoline and pyrazole derivatives. Molecules 2013;18:2683-711.

24. Nosrat BS, Mahmoodi O, Mamaghani M. Facile regioselective synthesis of novel bioactive thiazolyl-pyrazoline derivatives via a three-component reaction and their antimicrobial activity. Bioorg Med Chem Lett 2013;23:548-51.

25. Rani M, Mohamad Y. Synthesis, studies and in vitro antibacterial activity of some 5-(thiophene-2-yl)-phenyl pyrazoline derivatives. J Saudi Chem Soc 2014;18:411-7.

26. Vidhya KR, Shafi SS. Synthesis, characterization and antimicrobial studies of novel 2-pyrazoline derivatives. Scholars Res Library Pharm Chem 2014;6:283-7. 
27. Desai KG, Naik JI, Jignesh P, Raval JP, Desai KR. Microwaveinduced and conventional heterocyclic synthesis: an antimicrobial entites of newer quinazolinyl- $\Delta^{2}$-pyrazolines. Arabian J Chem 2014;7:597-603.

28. Bhat KI, Jainey PJ. Cytotoxic and antimicrobial studies of some substituted pyrazoline derivatives derived from acetyl hydrazines. Asian J Pharm Clin Res 2014;7:237-9.

29. Viveka S, Sharma D, Nagaraja P, Ballav GK, Kerkar S. Design and synthesis of some new pyrazolyl-pyrazolines as potential antiinflammatory, analgesic and antibacterial agents. Eur J Med Chem 2015;101:442-5.

30. Alam MS, Bano S, Javed K, Dudeja M, Dhulap A. Synthesis, biological evaluation and molecular docking of some substituted pyrazolines and isoxazolines as potential antimicrobial agents. Eur J Med Chem 2015;95:96-103.

31. Prajuli R, Banerjee J, Khanal H. Synthesis of some pyrazolone derivatives and evaluation of its antibacterial and cytotoxic activity. Orient J Chem 2015;31:2099-106.

32. Sulthana SS, Antony SA, Balachandran C, Shafi SS. Thiophene and benzodioxole appended thiazolyl-pyrazoline compounds: microwave-assisted synthesis, antimicrobial and molecular docking studies. Bioorg Med Chem Lett 2015;25S:2753-7.

33. Altıntop MD, Ozdemir A, Zitouni GT, Ilgın S, Kaplancikli ZA. A novel series of thiazolyl-pyrazoline derivatives: synthesis and evaluation of antifungal activity, cytotoxicity and genotoxicity. Eur J Med Chem 2015;92:342-52.

34. Indorkar D, Chourasia OP, Limaye SN. Synthesis and characterization of some new synthesis of 1-acetyl-3-(4nitrophenyl)-5-(substituted phenyl) pyrazoline derivative and antimicrobial activity. Int J Curr Microbiol Appl Sci 2015;4:670-8.

35. Karangiya K, Upadhyay J. Synthesis and antimicrobial screening of new pyrazolines derived from chalcones of vanillin analog. Int J Pharm Sci Drug Res 2016;8:98-102.

36. Ahmad A, Husain A, Khan SA, Mujeeb M, Bhandari A. Synthesis, antimicrobial and antitubercular activities of some novel pyrazoline derivatives. J Saudi Chem Soc 2016;20:577-84.

37. Muneera MS, Joseph J. Design, synthesis, structural elucidation, pharmacological evaluation of metal complexes with pyrazoline derivatives. J Photochem Photobiol B 2016;163:5768.

38. Sid A, Messai A, Parlak C, Kazanci N, Keasan G, Rhyman L, et al. 1-Formyl-3-phenyl-5-(4-isopropylphenyl)-2-pyrazoline: synthesis, characterization, antimicrobial activity and DFT studies. J Mol Struct 2016;1121:46-53.

39. Patel NB, Sheikh FM, Patel HR, Rajani D. Synthesis of 2pyrazolines from pyridine based chalcones by conventional and microwave-assisted techniques: their comparison and anti-microbial studies. J Saudi Chem Soc 2016;20:451-6.

40. Shamsuzzaman KH, Dar AM, Siddiqui N, Rehman S. Synthesis, characterization, antimicrobial and anticancer studies of new steroidal pyrazolines. J Saudi Chem Soc 2016;20:7-12.

41. Karad SC, Purohit VB, Thakor P, Vasudev P, Thakkar R, Raval DK. Novel morpholinoquinoline nucleus clubbed with pyrazoline scaffolds: synthesis, antibacterial, anti-tubercular and antimalarial activities. Eur J Med Chem 2016;112:270-9.

42. Shah TJ, Sudani BR, Desai VA. Correlation of two pyrazoline moiety in a single molecule via $\mathrm{N}$-linkage containing fluorine atom as a substituent and their biological significance. Int J Curr Pharm Res 2016;8:28-31.

43. Desai NC, Patel BY, Dave BP. Synthesis and antimicrobial activity of novel quinoline derivatives bearing pyrazoline and pyridine analogues. Med Chem Res 2017;26:109-17.

44. Mishra VK, Mishra M, Kashaw V, Sushil K. Kashaw SK. Synthesis of 1,3,5-trisubstituted pyrazolines as potential antimalarial and antimicrobial agents. Bioorg Med Chem 2017;25:1949-62.

45. Rashmi S, Ajay MC. Microwave-assisted synthesis of some substituted 2-pyrazoline-a green approach. Int J Adv Res 2017:5:342-6.

46. Sadashiva R, Naral D, Kudva J, Kumar SM, Kumsi M. Synthesis, structure, characterization, in vitro and in silico biological evaluation of a new series of thiazole nucleus integrated with pyrazoline scaffolds. J Mol Struct 2017;1145:18-31.

47. Umadevi R. Synthesis and antimicrobial activity of chalcones and pyrazolines. Int J Pharm Chem 2017;7:115-20.

48. Kumarswami D, Prashanth D. Synthesis and evaluation of pyrazoline derivatives as antibacterial agents. Int J Pharm Bio Sci 2017;7:84-93.

49. Yusuf M, Solanki I. Synthesis and antimicrobial studies of furyl based new bispyrazolines linked via aliphatic chains. J Saudi Chem Soc 2017;21:251-61.

50. Burmidjiza A, Muskinja J, Ratkovic Z, Kosanic M, Rankovic B, Novakovic SB. Pyrazoline derivatives of acryloyl substituted ferrocenyl ketones: synthesis, antimicrobial activity and structural properties. Inorg Chem Acta 2018;471:570-6.

51. Slilveri S, Basaboina N, Vamaraju HB, Raj S. Design, synthesis, molecular docking, ADMET studies and biological evaluation of pyrazoline incorporated 1,2,3 triazole benzene sulphonamides. Int J Pharm Pharma Sci 2019;11:6-15.

52. Asad M, Arshad MN, Khan SA, Ataualpa MO, Braga AC Cyclization of chalcones into N-propionyl pyrazolines for their single-crystal X-ray, computational and antibacterial studies. J Mol Struct 2020;120:127-6. 